\title{
Truncated Forms of DNA-binding Estrogen Receptors in Human Breast Cancer
}

Gary K. Scott, “ Peter Kushner," Jean-Louis Vigne, ${ }^{*}$ and Christopher C. Benz*

${ }^{*}$ Cancer Research Institute, ${ }^{\ddagger}$ Reproductive Endocrinology, and ${ }^{\S}$ Metabolic Research Unit,

University of California, San Francisco, California 94143-0128

\begin{abstract}
The likelihood a breast cancer will respond to antiestrogen therapy depends on the tumor content of immunoreactive or ligandbinding estrogen receptor (ER). To investigate the failure of many ER-positive breast cancers to respond to antiestrogen therapy, we examined by gel-shift assay the ability of tumor ER to bind its cognate estrogen response element (ERE). Analysis of 38 primary breast cancers showed that some tumors containing abundant immunoreactive ER failed to demonstrate DNA binding ER. In many other ER-positive tumors, the fraction of DNA binding ER was low and consisted primarily of truncated receptor forms, which on Western analysis were revealed to be $50 \mathrm{kD}$ homodimers and 67-50 kD ER heterodimers. The use of protease inhibitors during tumor extraction and the demonstration of nuclear-localizing ER and ERE-binding COUP (chicken ovalbumin upstream promoter) protein in these tumors indicated that the truncated forms of ER were likely present in vivo. The presence of intact DNA binding ER correlated with higher tumor content of immunoreactive sex steroid receptors (ER and/or PR), standard predictors of tumor responsiveness to antiestrogen, suggesting that loss or truncation of DNA binding ER may be an important prognostic parameter accounting for some forms of clinical resistance to antiestrogen therapy. ( $J$. Clin. Invest. 1991. 88:700-706.) Key words: gel-shift assay • immunoreactive ER • estrogen response element
\end{abstract}

\section{Introduction}

Most patients with breast cancer are treated with either chemotherapy or antiestrogenic agents. The likelihood a breast tumor will respond to antiestrogen (e.g., tamoxifen) therapy depends on the tumor level of estrogen receptor $(E R)^{1}$ as measured by

Portions of this work were presented at the annual meetings of the American Federation for Clinical Research and were published in abstract form (1990. Clin. Res. 38:31).

Address correspondence and reprint requests to Dr. Christopher C. Benz, M-1282 Cancer Research Institute, University of California, San Francisco, CA 94143-0128.

Received for publication 7 February 1991 and in revised form 22 April 1991

1. Abbreviations used in this paper: COUP, chicken ovalbumin upstream promotor; ER, estrogen receptor, ERE, estrogen response element; PR, progesterone receptor; RAR, retinoic acid receptor; THR, thyroid hormone receptor.

J. Clin. Invest.

(c) The American Society for Clinical Investigation, Inc. 0021-9738/91/08/0700/07 \$2.00

Volume 88, August 1991, 700-706 radioligand binding or immunochemical assay (1-3). Progesterone receptor (PR) content is also determined because it provides some indication that the tumor ER is functional and capable of inducing synthesis of PR (4), although examples of breast cancers that express PR independent of ER are well known $(5,6)$. Unfortunately, $20-30 \%$ of $E R+/ P R+$ tumors and up to $60-70 \%$ of $E R+/ P R$ - tumors fail to respond to antiestrogen therapy for reasons that are poorly understood (1-3). Some studies suggest that these endocrine-resistant tumors contain dysfunctional ER (3-11). Because the early identification of such endocrine-resistant tumors would allow patients to be started on alternative forms of therapy, investigators have been trying to develop assays to detect dysfunctional ER (811). To date, however, these assays have been difficult to implement and have not identified specific enzymatic or structural defects correlating with the clinical prevalence of endocrine-resistant ER+ breast cancers.

Current immunochemical and radioligand measurements of ER content are based on the integrity of the receptor protein's most $\mathrm{COOH}$-terminal hinge and steroid recognition domains, without regard to structural or functional abnormalities that might exist within its more $\mathrm{NH}_{2}$-terminal regions including the highly conserved zinc-finger DNA binding domain (12-18). As with other members of the nuclear receptor superfamily, ER regulation of gene expression occurs by the binding of ligand-occupied $67 \mathrm{kD}$ receptor dimers to a defined estrogen responsive element (ERE) usually located within the promoter region of each target gene (16-18). Rare and heritable clinical disorders involving defective steroid receptors have been linked to genetic mutations in specific receptor domains (19). Mutations resulting in altered amino acids in the ER ligand binding domain as well as transcriptional splicing errors causing deleted portions of entire ER domains have also been reported in some human breast tumors and cell lines (20-22). In addition to these primary genetic events, it is also possible that posttranslational receptor modifications occur in some tumors and lead to functionally disabled ER with intact $\mathrm{COOH}$-terminal domains $(23,24)$. The differential susceptability of specific ER domains to endoproteolytic cleavage has long been recognized and accounts for the ligand binding meroreceptors (3S) that are often isolated along with intact (4-8S) ER from estrogen responsive tissues (23). In fact, a steroid-inducible protease activity has been found in normal reproductive tissues that produces $\mathrm{NH}_{2}$-terminally truncated nuclear-localizing $\mathrm{ER}(\sim 50$ $\mathrm{kD}$ ), suggesting that there may be a physiological role for this form of posttranslational ER modification (25-27). Endogenous cleavage of $67 \mathrm{kD}$ ER and formation of an $\sim 50 \mathrm{kD}$ nuclear receptor product appears to be associated with the progression to hormonally-independent breast tumors in some murine models, and this has led investigators to suggest that truncated DNA binding ER may compete for available target gene 
response elements, interfering with normal receptor regulated gene transcription (28).

Gel-shift analysis provides a sensitive means of assaying relatively pure receptor proteins for high affinity, high specificity DNA binding function $(29,30)$; however, these assays have not yet been applied to the functional assessment of receptors from extracts of primary human tumors. We developed stringent assay conditions that eliminate most nonspecific DNA binding by proteins present in the high salt extracts of both primary breast tumor samples and cultured breast cancer cells. The DNA binding affinity and specificity of this assay was initially confirmed by comparing ER complexes formed with a synthetic 35-mer containing either the ERE consensus sequence (5'-GGTCACAGTGACC-3'), or a base substituted ERE $_{m}$ sequence (5'-GGACACAGTGTCC-3') that preferentially binds progesterone, androgen, or glucocorticoid receptors (31). Because thyroid hormone receptors (THR), retinoic acid receptors (RAR), ER, and the recently cloned transcriptional factor known as COUP (chicken ovalbumin upstream promoter) all possess near equivalent ERE binding affinity and specificity and may be found in human tissue samples (16-18, 32,33 ), antibodies to ER and COUP are presently used to confirm the identity of proteins found in the gel-shifted ERE complexes. Using this assay system to screen for DNA binding ER (ER-ERE) contained in primary breast tumor extracts, we now report on the high frequency of truncated DNA binding ER found in ER+/PR - breast tumors, as well as the fact that some tumors contain immunoreactive ER that appears unable to bind DNA or form ER-ERE complexes.

\section{Methods}

Whole-cell extracts were prepared for ER analysis using $~ 100-200$ mg of wet tumor weight or $10^{7}$ cultured cells. For assay standardization, partially purified human ER was obtained from nuclei of transfected Chinese hamster ovary cells $\left(\mathrm{CHO}^{\mathrm{ER}}\right)(12)$ that were isolated by douncing freshly harvested cells in $0.25 \mathrm{M}$ sucrose, pelleting twice through $1.7 \mathrm{M}$ sucrose cushions, homogenizing in a nuclear lysis buffer, and extracting receptor by ammonium sulfate precipitation and dialysis (34). Freshly excised tumors were carefully dissected before cryopreservation $\left(\leq-80^{\circ} \mathrm{C}\right)$; at the time of analysis these samples were pulverized to powder at liquid nitrogen temperature using a Bessman tissue pulverizer (Fisher Scientific Co., Pittsburgh, PA), placed into ice-cold extraction buffer (20 mM Tris pH 7.5, $10 \mathrm{mM}$ DDT, 20\% vol/vol glycerol, $0.4 \mathrm{M} \mathrm{KCl}$ ) with or without protease inhibitors (leupeptin $0.5 \mu \mathrm{g} / \mathrm{ml}$, phenylmethanesulfonyl fluoride $2 \mathrm{mM}$, antipain 10 $\mu \mathrm{g} / \mathrm{ml}$; Boehringer Mannheim Corp., Indianapolis, IN), and solubilized by Polytron (Brinkmann Instrs., Inc., Westbury, NY) homogenization. The whole-cell extracts were then centrifuged at $100,000 \mathrm{~g} \times 20$ min at $2^{\circ} \mathrm{C}$, supernatants collected, total immunoreactive ER assayed (Abbott ER-EIA, North Chicago, IL) and total protein content determined (Bradford assay; Bio-Rad, Richmond, CA). Before gel-shift electrophoresis extracts (10-50 $\mu \mathrm{g}$ total protein) were incubated with $2 \mu \mathrm{g}$ poly[d(I-C)] (Boehringer Mannheim Corp.) in $100 \mathrm{mM} \mathrm{KCl}, 10 \mathrm{mM}$ Tris pH 7.5, $20 \mathrm{mM}$ Tris pH 7.5, $2 \mathrm{mM}$ DTT, 5\% vol/vol glycerol at $0^{\circ} \mathrm{C} \times 15 \mathrm{~min}$; in addition, $10 \mathrm{pmol}$ of unlabeled nonspecific 20 -mer mix (shown below) was added to increase the stringency of the binding conditions between ER and ERE. The binding reaction was initiated by adding $10 \mathrm{fmol}\left(4 \times 10^{4} \mathrm{cpm}\right)$ of $\left[{ }^{32} \mathrm{P}\right]-5^{\prime}$ end-labeled duplexed ERE oligomers (shown below) and the mix incubated at $20^{\circ} \mathrm{C} \times 30 \mathrm{~min}$ in a final volume of $20 \mu \mathrm{l}$. The excess molar amount of ERE relative to ER in these reaction conditions was set to produce virtually complete ERERE formation given the known $K_{d}$ for this complex $\simeq 10^{-9} \mathrm{M}$ (35, 36). Complexes were then electrophoretically separated on a $4 \%$ loosely cross-linked (acrylamide/bisacrylamide $=30: 1$ ) nondenaturing gel, us- ing $0.5 \times$ TBE (50 $\mathrm{mM}$ Tris-50 $\mathrm{mM}$ boric acid-1 $\mathrm{mM}$ EDTA) as a running buffer, and the gel was then dried and autoradiographed to reveal complexed or free bands. To identify the protein bound in the retarded complexes, $0.05 \mu \mathrm{g}$ of antibody was added to the incubation mix to observe supershifting of the ERE bound complexes. Murine monoclonal antibodies to human ER (D75, H222, H226) were supplied by G. L. Greene (37), and high titer rabbit anti-COUP antiserum was supplied by M.-J. Tsai (33). The ERE binding specificity of the complexes was confirmed by substituting labeled mutant $\mathrm{ERE}_{\mathrm{m}}$ sequences (shown below) to observe loss of the gel-retarded complexes. Synthetic duplexed and single-stranded DNA oligomers used for this procedure were:

duplexed ERE:

5' GTCCAAAGTCAGGTCACAGTGACCTGATCAAAGTT 3'; duplexed $\mathrm{ERE}_{\mathrm{m}}$ :

5' GTCCAAAGTCAGGACACAGTGTCCTGATCAAAGTT 3';

1:1 mix of single-stranded 20-mers:

\section{5' GAAGCTGAGATTCCCCTCCA 3 '}

5' GGCTTGGGATGGAGTAGGAT 3'.

For Western blot analysis of ER containing tumor extracts, samples were boiled in SDS $(1 \%)$ and DTT $(100 \mathrm{mM})$, run on SDS-polyacrylamide gels (10\%), membrane transferred (Immobilon-P; Millipore, Bedford, MA), and ER detected by hybridization with monoclonal antibody (H222) and secondary reaction to rabbit anti-rat IgG and ${ }^{125} \mathrm{I}$-Protein A (100 $\mu \mathrm{Ci} / \mu \mathrm{g}$; NEN DuPont, Wilmington; DE). In some studies the gel-shifted free and DNA bound receptor was membrane transferred in methanol-tris-glycine (20\%, $25 \mathrm{mM}, 192 \mathrm{mM}$; pH 8.3) buffer and detected by monoclonal antibody hybridization as a gelshift immunoblot assay.

\section{Results and Discussion}

Gel-shift analysis of purified $67 \mathrm{kD}$ human ER, derived from a stably transfected $\mathrm{CHO}^{\mathrm{ER}}$ expressing $\geq 10^{6} \mathrm{ER}$ molecules per cell (12), produces a single gel-retarded band referred to as isoform $a$, as shown in Fig. $1 A$. Coincubation of this purified ER with anti-ER monoclonals (H222, D75, H226) produces a supershift of isoform $a$, consistent with the increased size of the antibody bound ER-ERE complex. A more complex gel-shift pattern results from assay of whole-cell MCF-7 human breast cancer extracts containing $\geq 2 \times 10^{4} \mathrm{ER}$ molecules per cell. These whole-cell ER extracts produced a much broader gelshifted band composed of ER-ERE isoform $a$ (recognized by both D75 and H226) and abundant amounts of COUP-ERE complex (whose mobility is similar to the ER-ERE isoform $b$ ), recognized by the highly specific anti-COUP antibody. These studies indicated that gel-shift analysis could detect as little as 0.1 fmol of DNA bound ER from whole-cell extracts containing $50 \mu \mathrm{g}$ of total protein including other ERE cross-reacting members of the steroid receptor superfamily (COUP, THR, RAR).

Many ER-positive breast tumors (e.g., extract $\mathrm{E}$ in Fig. $1 \mathrm{~A}$ ) were found to contain an enzymatic activity that could convert isoform $a$ into two additional gel-retarded bands with increased gel mobility, isoforms $b$ and $d$. This activity could be inhibited by heat pretreatment or by coincubation of tumor extracts with protease inhibitors, but not by phosphatase inhibitors such as molybdate or vanadate. When ERE was allowed to bind to purified ER before the addition of uninhibited tumor extract minimal conversion of isoform $a$ occurred, indicating that receptor dimerization and DNA binding protected ER from this 


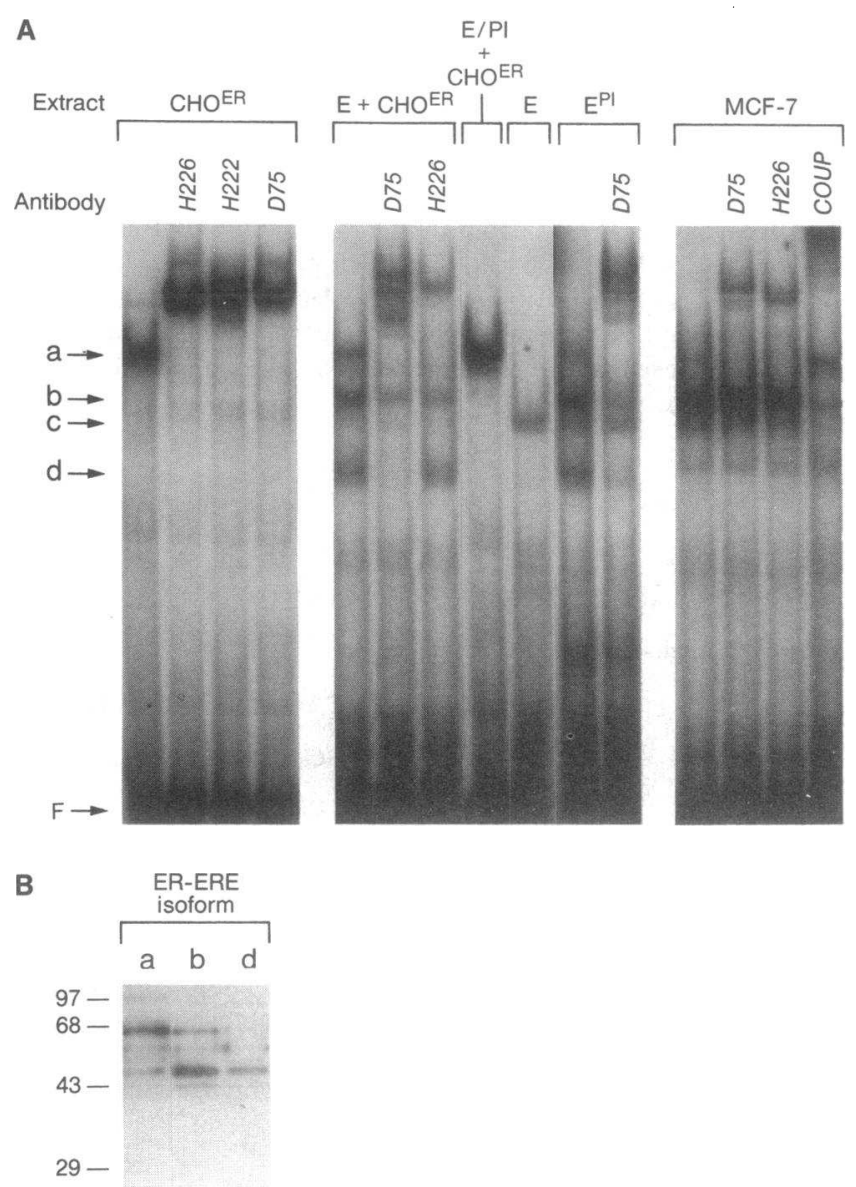

Figure 1. Detection and composition of DNA binding estrogen receptor (ER-ERE) isoforms. $(A){ }^{32} \mathrm{P}$-Labeled DNA (ERE) incubated with either purified ER extracted from $\mathrm{CHO}^{\mathrm{ER}}$ cells, or ER-containing whole-cell extracts from a primary breast tumor sample No. 90 (E) or cultured human breast cancer cells (MCF-7), produces gel-shifted DNA-protein complexes $(a, b, c$, and $d)$ distinguishable after autoradiography from the free unbound DNA $(F)$. In the presence of coincubated anti-ER monoclonals $(\mathrm{H} 226, \mathrm{H} 222, \mathrm{D} 75)$ or a polyclonal antibody against the COUP transcription factor, the gel-shifted DNA complexes containing either ER (ER-ERE isoforms $a, b$, and $d$ ) or COUP are supershifted due to the additional size of the antibody complex. $\mathrm{CHO}^{\mathrm{ER}}$ produces only ER-ERE isoform $a$. MCF-7 cells produce predominantly ER-ERE isoform $a$ with substantial COUPERE. Extract $\mathrm{E}$ produces only complex $c$. Extract $\mathrm{E}^{\mathrm{PI}}$ (similarly prepared from tumor No. 90 except that protease inhibitors were added before tissue homogenization) produces isoforms $a, b$, and $d$. When one-tenth volume of extract $\mathrm{E}$ is preincubated briefly with $\mathrm{CHO}^{\mathrm{ER}}$, isoforms $b$ and $d$ are formed along with a proportional loss in isoform $a$; this isoform-converting activity in $\mathrm{E}$ can be completely prevented by the addition of protease inhibitors (PI). D75 causes a supershift of ER-ERE isoforms $a, b$ (partial), and $d ; \mathrm{H} 226$ only supershifts isoform $a$. None of the anti-ER antibodies recognize complex $c$ (not shown). (B) Gel-shifted ER-ERE isoforms $a, b$, and $d$ derived from CHO ${ }^{\mathrm{ER}}$ were individually cut from the gel, denatured, reduced, and analyzed by standard Western-blot technique (using $\mathrm{H} 222$ antibody) to reveal their ER composition; prestained protein molecular weight markers ran as indicated.

apparent proteolytic activity. The $\mathrm{COOH}$-terminal-specific antibodies, D75 and H222, recognized all three isoforms; however, the $\mathrm{NH}_{2}$-terminal-specific antibody, $\mathrm{H} 226$, recognized only isoform $a$, suggesting that $\mathrm{NH}_{2}$-terminal epitopes of isoforms $b$ and $d$ were either lost or obscured under the nondenaturing gel-shift assay conditions. To determine the molecular composition of receptor present in each of the various ER-ERE isoforms, purified ER was preincubated with uninhibited tumor extract, gel-shifted, and the $a, b$, and $d$ isoform bands excised and individually subjected to Western analysis. Fig. $1 B$ demonstrates that isoform $a$ contained only $67 \mathrm{kD} \mathrm{ER}$, while $b$ and $d$ isoforms contained truncated $50 \mathrm{kDa}$ ER present as ERE bound heterodimers and homodimers, respectively. The 67 and $50 \mathrm{kD}$ ER were recognized by both $\mathrm{H} 222$ and $\mathrm{H} 226$ monoclonals on Western analysis, suggesting that the loss of $b$ and $d$ isoform recognition by $\mathrm{H} 226$ during gel-shift analysis was not due to epitope loss but rather altered receptor conformation under the nondenaturing gel-shift assay conditions.

These preliminary findings indicated that the proteolytic activity contained in some breast tumor extracts could potentially modify the gel-shift recognition of DNA bound ER. To assess our ability to arrest proteases that might be activated during tumor extraction, a tumor sample with high protease content was reextracted in the presence of protease inhibitors and assayed again for DNA binding ER (see lane $\mathrm{E}^{\mathrm{PI}}$ in Fig. 1 $A$ ). The uninhibited tumor extract produced only a single gelshift complex $c$, which was not supershifted by any of the antiER monoclonals. In contrast, the protease inhibited extract $\left(E^{\mathrm{PI}}\right)$, containing an equivalent amount of immunoreactive ER, produced abundant ER-ERE complex supershifted by D75, with over $50 \%$ of the total DNA bound ER identifiable as isoform $a$. Thus, protease inhibitors added at the time of tumor processing appear to be necessary and sufficient to extract intact DNA binding ER from breast tumors, even those highly enriched in protease activity.

We similarly compared ER-ERE formation from other receptor-positive tumor extracts ( $\geq 20 \mathrm{fmol} \mathrm{ER/mg} \mathrm{total} \mathrm{pro-}$ tein) prepared in the presence or absence of protease inhibitors. Three representative examples are shown in Fig. $2 A$ to illustrate the variable extent of isoform modification from protease activity present during tumor processing and extract incubation before DNA binding. In these cases the proteolysis and conversion of isoforms occurred without significant change in total immunoreactive ER content as routinely measured by two different $\mathrm{COOH}$-terminal anti-ER monoclonals, D547 and H222. In one tumor sample (No. 1222), the ex vivo proteolysis resulted in the loss of $b$ and $d$ isoforms, leaving only a gel-shifted $c$ complex like that shown in Fig. 1. In another sample (No. 226), the ex vivo proteolysis was less complete, converting predominantly $a$ isoform into $b$ and $d$ isoforms along with some $c$ complex. In a third sample (No. 88), ex vivo proteolysis enhanced the amount of preexisting $c$ complex but none of the remaining DNA bound protein complex was supershifted by any of the anti-ER monoclonals (D75, H222, H226), even in the protease-inhibited tumor extract. Western blots of these sample extracts performed using $\mathrm{H} 222$ or $\mathrm{H} 226$ antibody detected varying amounts of 67 and $50 \mathrm{kD} \mathrm{ER}$, as shown in Fig. 2 B. In some samples (e.g., No. 1222) the ex vivo truncation of 67 to $50 \mathrm{kD} \mathrm{ER}$ was particularly evident. In other samples ER truncation was either minimal (e.g., No. 226) or already complete (e.g., No. 88), having occurred either in vivo or before extract preparation.

The failure of some tumor extracts, such as proteolyzed No. 1222 and protease-inhibited No. 88, to form any gel-shifted ER-ERE isoforms was surprising because they contained abun- 
A

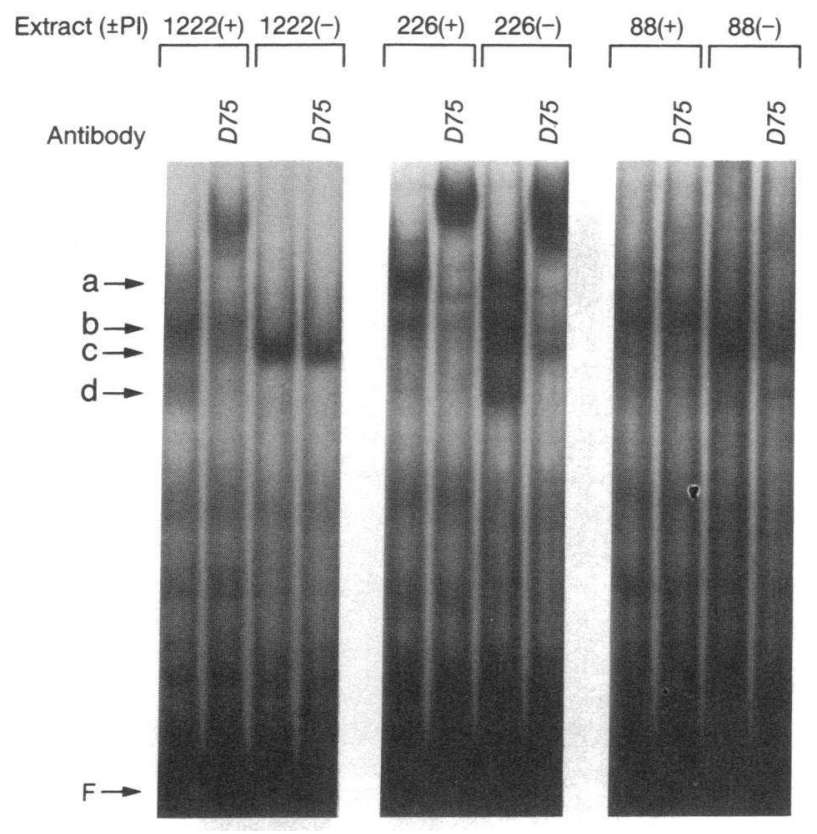

B

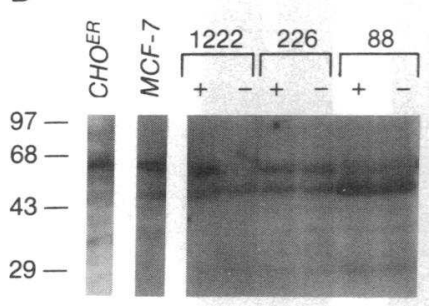

C

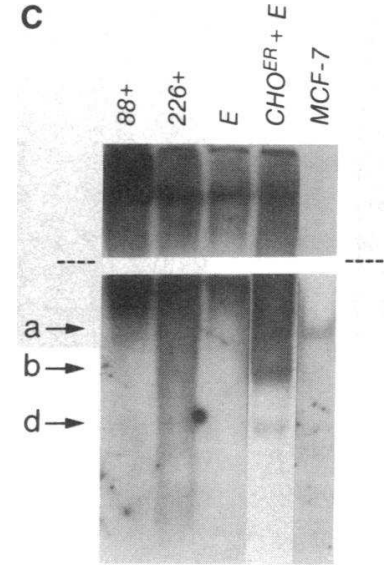

Figure 2. DNA binding and nonbinding immunoreactive ER from representative breast tumor samples. Extracts containing $>50 \mathrm{fmol}$ $\mathrm{ER} / \mathrm{mg}$ protein from three primary breast tumors (\#1222, \#226, \#88) were freshly prepared in the presence $(+)$ or absence $(-)$ of protease inhibitors $(P I)$ and used for both gel-shift assays $(A$ and $C)$ and Western (immuno-) blotting ( $B$ and $C$ ). Samples 1222( + ) and 226(+) contain $0.55 \mathrm{fmol}$ ER per lane, $1222(-)$ and $226(-)$ contain $0.74 \mathrm{fmol}$ ER per lane, 88(+) and 88(-) contain $0.30 \mathrm{fmol}$ ER and $0.40 \mathrm{fmol}$ ER per lane, respectively. $(A)$ Gel-shift assays resolve separate DNA bound complexes $a, b, c$, and $d$; anti-ER monoclonal D75 was used to confirm the finding of ER-ERE isoforms in 1222(+), 226(+), and $226(-)$, that were not found in $1222(-), 88(+)$, or $88(-)$. (B) A standard Western analysis shows the relative proportions of intact $(67 \mathrm{kD})$ and truncated $(\leq 50 \mathrm{kD})$ immunoreactive ER in control and tumor extracts prepared in the presence $(+)$ or absence $(-)$ of protease inhibitors; prestained protein molecular weight markers ran as indicated. (C) Tumor extracts $88+$ and $226+$ along with control samples $\mathrm{E}, \mathrm{CHO}^{\mathrm{ER}}+\mathrm{E}$, and MCF-7 (as described in Fig. 1), were gel-shift immunoblotted and the probed membrane divided (dotted lines) for separate autoradiography to reveal both the non-DNA binding ER ( 3 $h$ exposure) and the DNA binding ER (15-h and 4-d exposures). DNA bound ER is shown below the dotted lines as isoforms $a, b$, or $d$ in samples 226+ and MCF-7 (4-d exposures), and in the combination of $\mathrm{CHO}^{\mathrm{ER}}+\mathrm{E}$ (15-h exposure). No DNA bound ER is detectable

dant immunoreactive $50 \mathrm{kD}$ ER which should possess intact (although possibly modified) DNA binding domains enabling the formation of isoform $d$. To demonstrate directly the abundance of non-DNA binding ER present in these sample extracts, gel-shift assays were run with unlabeled ERE, electroblotted, and probed as Westerns using the H222 antibody (Fig. $2 C)$. From these gel-shift immunoblots we were able to observe that primary tumor extracts contained apparent non-DNA binding ER that migrated more slowly than DNA bound ER in the nondenaturing gels, consistent with the mildly acidic isoelectric $\mathrm{pH}$ of intact and truncated $\operatorname{ER}(38,39)$, and in amounts inversely related to the proportion of ER-ERE isoform $a$. This non-DNA binding ER appeared to have resulted from a protease-independent mechanism in as much as $\mathrm{CHO}^{\mathrm{ER}}$ or MCF7-derived extracts produced no unbound ER detectable by gelshift immunoblot assay even after proteolytic pretreatment (Fig. 2 C). Because the content of total immunoreactive ER (by Abbott EIA assay) was nearly equivalent in each of the sample extracts analyzed for Fig. $2 C$ (except $\mathrm{CHO}^{\mathrm{ER}}$ ), we have no obvious explanation to account for the greater immunoreactivity of unbound ER over that present in the ER-ERE isoforms apparent after gel-shift immunoblotting. Furthermore, the quantitative immunochemical assay for ER depends on recognition of two different $\mathrm{COOH}$-terminal ER epitopes under nondenaturing incubation conditions. Thus, it is unlikely that the antibody failure to supershift ER from samples, such as No. 88 under similar nondenaturing conditions (Fig. $2 \mathrm{~A}$ ), could be accounted for by either lost or conformationally obscured epitopes. More likely, some forms of $50 \mathrm{kD} \mathrm{ER}$, such as that found in sample No. 88 (Fig. 2 C), are unable to bind DNA due to an additional change that affects its DNA binding domain. Preliminary analysis of cloned ER cDNA from tumor No. 88 indicates a normal ER mRNA sequence particularly in the DNA binding domain (unpublished), suggesting that the loss of DNA binding ability by this tumor's ER has occurred as a posttranslational modification of the ER protein. Sequence alterations in the DNA binding domain of some sex steroid receptors have been associated with hormone-resistant human disease (40). However, direct sequencing and chemical mismatch cleavage screening have failed to identify altered transcriptional sequences in the DNA binding domain of nearly $20 \mathrm{ER}+/ \mathrm{PR}-$ human breast tumors studied to date (S. Fuqua, personal communication), suggesting that this is not the mechanism accounting for our observations of non-DNA binding ER in human breast tumors.

We also measured COUP polypeptide binding to ERE and checked immunohistological localization of ER in the residual portions of frozen tumor samples to determine if receptor degradation occurred after surgical resection (despite immediate cryopreservation at $-80^{\circ} \mathrm{C}$ ) and before protease inhibition during extract preparation. Fig. $3 A$ shows that tumor samples (No. 1222 and 88) extracted in the absence of protease inhibitors formed no detectable COUP-ERE complexes while the same samples processed in the presence of protease inhibitors possessed comparable levels of ERE-binding COUP polypep-

in samples $88+$ or $\mathrm{E}$ ( $4 \mathrm{~d}$ exposures). The non-DNA binding ER is shown above isoform $a$, predominantly in the upper autoradiography panel (above the dotted lines), where it appears as a more slowly migrating protein band in samples $88+, 222+$, and $\mathrm{E}$, not present in MCF-7 or pure $\mathrm{CHO}^{\mathrm{ER}}$. 
A.

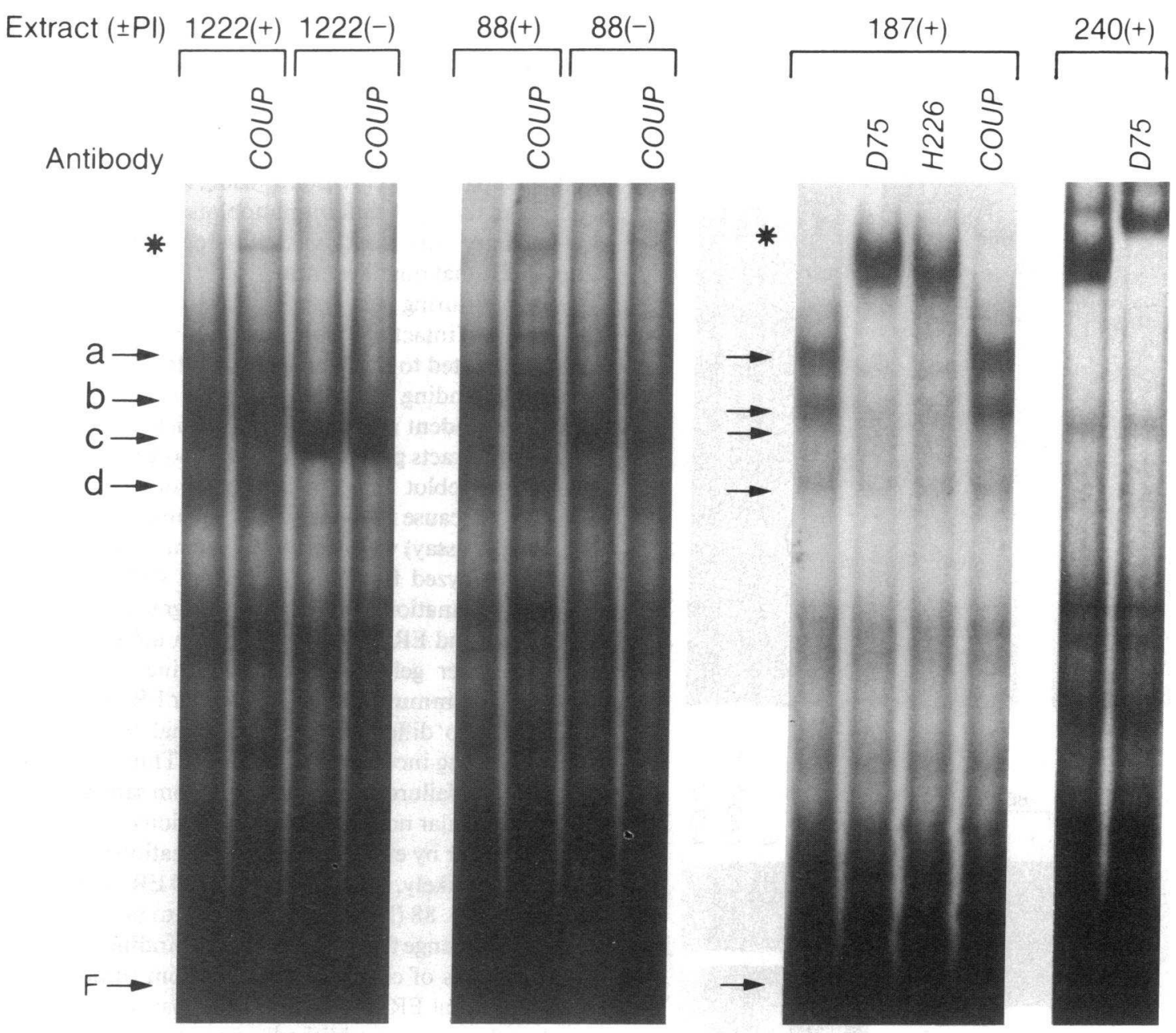

B.

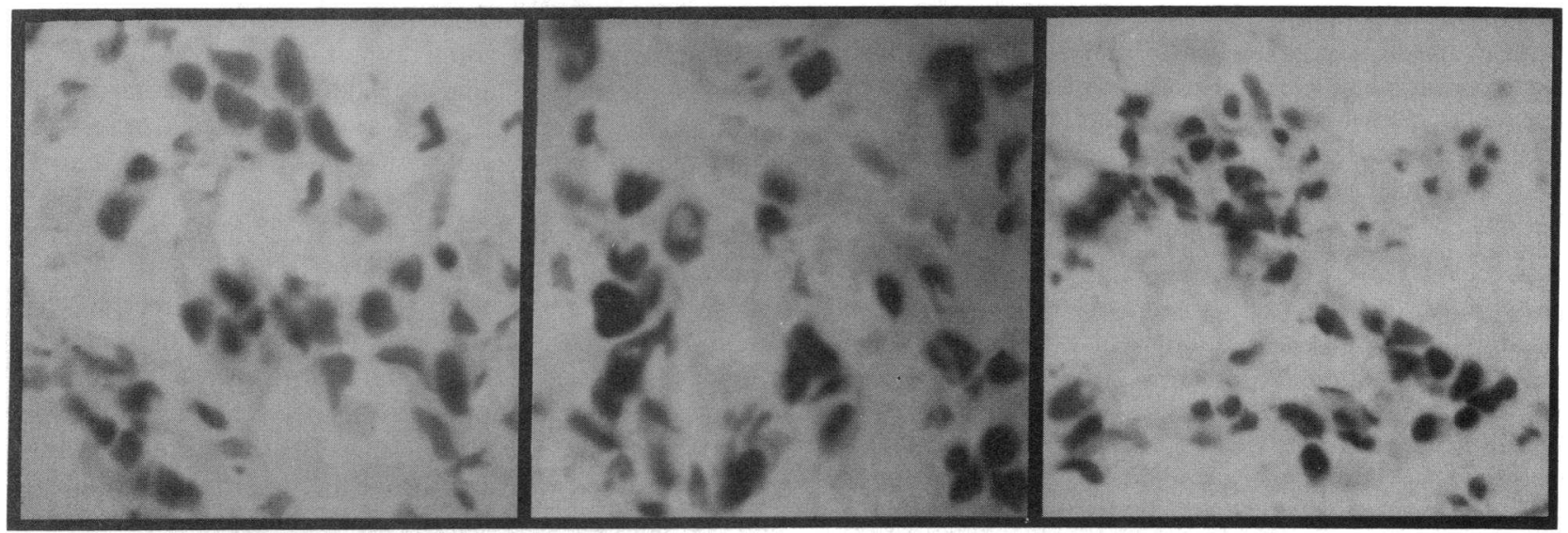

Figure 3. Intact DNA binding COUP protein and immunohistochemical preservation of ER in tumors with abnormal DNA-binding ER. (A) Gel-shift analysis of ER+ (> $50 \mathrm{fmol} / \mathrm{mg}$ protein) primary tumor samples $(1222,88,187,240)$, extracted in the presence $(+)$ or absence $(-)$ of protease inhibitors $(P I)$, revealed protein-DNA complexes that were supershifted by either COUP polyclonal antibody or anti-ER monoclonals (D75, H226). Asterisks indicate the migration of antibody supershifted COUP complexes (the COUP supershifted band for sample No. 187 is only faintly visible on this exposure). DNA-binding COUP was detected in all +PI but not in the -PI tumor extracts. Sample 240 did not contain the usual ER-ERE isoforms $(a, b$, or $d)$ but contained a higher migrating complex that was supershifted by D75. (B) Immunohistochemical staining revealed comparable patterns of nuclear-localizing ER (immunoperoxidase ER-ICA assay, Abbott Labs, with hematoxylin counterstain) in sections of cryopreserved breast tumors that yielded different amounts of ER-ERE isoforms by gel-shift assay. 
tide. These results indicated that COUP, like ER, is susceptable to ex vivo proteolytic degradation; therefore, the loss of $67 \mathrm{kD}$ ER and inability to produce ER-ERE isoform $a$ from proteaseinhibited extracts containing intact DNA binding COUP (e.g., No. 1222 and 88 ) likely reflected the in vivo state of these tumors rather than postsurgical ER degradation. Furthermore, the excellent cytological preservation and the presence of nuclear-localizing ER in these samples (Fig. $3 \mathrm{~B}$ ) confirmed that these cryopreserved tumors did not suffer from significant ex vivo cellular degradation.

38 primary breast tumors were analyzed by gel-shift assay after ER extraction in the presence of protease inhibitors. The ER-ERE isoform profiles shown for the protease-inhibited extracts from tumors No. 1222, 226, and 187 were representative of virtually all the receptor-positive breast tumors studied. Samples with complete absence of immunoreactive DNA binding ER (e.g., No. 88) were uncommon, as was the finding of an abnormally large (more slowly migrating) ER-ERE complex (e.g., No. 240 in Fig. 3). Western blotting of this latter tumor extract demonstrated immunoreactive ER of usual size $(\leq 67$ $\mathrm{kD}$ ); as well, the complex formed from this nuclear-localizing ER was susceptable to proteolysis, not disaggregated by RNase, unreactive to various heat-shock antibodies, and not produced on incubation with $\mathrm{ERE}_{\mathrm{m}}$ instead of ERE. The nature of this unusually large ER-ERE complex remains to be determined. To assess the prevalence and potential clinical significance of tumors lacking intact DNA binding ER, we compared total immunoreactive ER and PR content in all tumors analyzed by gel-shift assay. Protease-inhibited tumor extracts were scored by gel-shift assay as positive only if ER-ERE isoform $a$ represented the most abundant form $(\geq 50 \%)$ of the total DNA bound ER (e.g., No. 187 and 226). Samples with a total lack of DNA binding ER (e.g., No. 88), or producing only a minor component (<50\%) of ER-ERE isoform $a$ (e.g., No. 1222), were scored as negative. Of the six samples with trace ER content $(0-19 \mathrm{fmol} / \mathrm{mg}$ protein $)$ that were analyzed, all scored negative for intact DNA binding ER including one PR+ sample that possessed a DNA binding protein with preferred affinity for $\mathrm{ERE}_{\mathrm{m}}$ (unreactive to anti-ER antibodies), consistent with its content of $>100 \mathrm{fmol} \mathrm{PR} / \mathrm{mg}$ protein. Of the remaining 32 ER+ tumor extracts, $18(56 \%)$ scored positive for abundant ER-ERE isoform $a$. Because the absolute content of tumor ER and $P R$ are each predictors of clinical response to antiestrogen therapy, we correlated our gel-shift scores with receptor levels as measured blindly and independently using commercial immunoassay kits (Abbott Labs) on contiguous portions of the same cryopreserved tumors. Table I shows that intact DNA binding ER was detected in two-thirds of tumors containing high ER or PR content ( $\geq 100 \mathrm{fmol} / \mathrm{mg}$ protein), but was not found in the majority of tumors with either low-to-intermediate ER content (20-99 fmol/mg protein) or trace PR content (regardless of ER level). The abundance of ER-ERE isoform $a$ correlated significantly with ER $(P=0.002)$, PR $(P=0.01)$, and combined ER/PR $(P=0.0002)$ content.

In summary, a modified gel-shift assay procedure has been used to identify truncated DNA binding ER as well as nonDNA binding ER present in a significant fraction of steroid receptor positive primary breast tumors. The relative abundance of the structurally intact DNA binding ER correlated with the total amount of immunoreactive steroid receptor (ER and $P R$ ) and the expected incidence of endocrine responsiveness. The actual responsiveness of these receptor-positive tu-
Table I. Prevalance of DNA Binding ER (a Isoform) in Breast Tumors of Varying Receptor (ER, PR) Content

\begin{tabular}{llcl}
\hline & Receptor content* & ER-ERE $a$ complex & \\
\hline ER & \pm & $0 / 6(0 \%)$ & \\
& + & $6 / 14(43 \%)$ & $P=0.002^{\S}$ \\
& ++ & $12 / 18(67 \%)$ & \\
PR & $?$ & $2 / 4(50 \%)$ & \\
& \pm & $2 / 11(18 \%)$ & \\
& + & $6 / 11(55 \%)$ & $P=0.010^{\S}$ \\
& ++ & $8 / 12(67 \%)$ & \\
ER/PR & $\pm / \pm$ & $0 / 5(0 \%)$ & \\
& $+/ \pm, \pm /++,++/ \pm$ & $3 / 12(25 \%)$ & $P=0.0002^{\S}$ \\
& $+/++,++/+,++/++$ & $13 / 17(47 \%)$ & \\
Total & & $18 / 38(47 \%)$ &
\end{tabular}

* Receptor content of 0-19 ( \pm ), 20-99 (+), or $\geq 100(++) \mathrm{fmol} / \mathrm{mg}$ protein cytosol; ?, not determined. ${ }^{\ddagger}$ ER-ERE $E_{a}=0-49 \%(-)$ or 50 $100 \%(+)$ of total anti-ER antibody recognized DNA complexes.

${ }^{\S}$ Significance test for linear trend in proportions, $\mathrm{Z}$ test $P$ values (42).

mors to endocrine therapy will not be known for many years because all of the primary tumors were diagnosed and resected within the past $3 \mathrm{yr}$. However, the significant association between loss of intact DNA binding ER and known predictors of tumor resistance to antiestrogen therapy (lower immunoreactive ER and lack of PR) supports the possibility that measuring the fraction of DNA binding ER may have important prognostic utility. It is provocative that the $67 \%$ prevalence of intact DNA binding ER found in those tumors with abundant PR and the $33 \%$ prevalence in tumors with minimal PR content are figures that match accepted antiestrogen response rates for these particular tumor subsets (1). Because a physiologically inducible ER endoprotease activity has been identified in rodent reproductive tissues (25-27), these gel-shift results detecting similarly truncated forms of ER in primary human breast tumors have encouraged further inquiry into posttranslational receptor modifying mechanisms associated with endocrine-resistant ER+ breast cancers. In preliminary studies using a nude-mouse model system to compare tamoxifen-resistant and tamoxifen-sensitive MCF-7 tumor growth, we have detected minor amounts of truncated $(\leq 50 \mathrm{kD})$ ER associated with excess endoprotease activity in the tamoxifen-resistant, receptor-positive breast tumors (41). With greater availability of cyropreserved human breast tumors collected from patients whose clinical response to tamoxifen is known, the predictive value of truncated forms of DNA-binding ER can be more fully evaluated.

\section{Acknowledgments}

We thank G. L. Green and M.-J. Tsai for providing anti-ER and antiCOUP antibodies; J. D. Baxter, G. L. Green and S. Fuqua for advice and helpful discussions; and D. Moore II for statistical assistance.

This work was supported by grants CA-44768 and CA-36773 from the National Cancer Institute and $\mathrm{CH}-235$ from the American Cancer Society. 


\section{References}

1. McGuire, W. L. 1980. Steroid hormone receptors in breast cancer treatment strategy. Recent Prog. Horm. Res. 36:135-156.

2. Manni, A. 1989. Endocrine therapy of metastatic breast cancer. J. Endocrinol. Invest. 12:357-372.

3. Holmes, F. A., H. A. Fritsche, J. W. Loewy, A. M. Geitner, R. C. Sutton, A. U. Buzdar, and G. N. Hortobagyi. 1990. Measurement of estrogen and progesterone receptors in human breast tumors: enzyme immunoassay versus binding assay. J. Clin. Oncol. 8:1025-1035.

4. McGuire, W. L., and G. M. Clark. 1983. The prognostic role of progesterone receptors in human breast cancer. Semin. Oncol. 10:2-6.

5. Horwitz, K. B., M. B. Mockus, and B. A. Lessey. 1982. Variant T47D human breast cancer cells with high progesterone-receptor levels despite estrogen and antiestrogen resistance. Cell. 28:633-642.

6. Reiner, G. C. A., and B. S. Katzenellenbogen. 1986. Characterization of estrogen and progesterone receptors and the dissociated regulation of growth and progesterone receptor stimulation by estrogen in MDA-MB-134 human breas cancer cells. Cancer Res. 46:1124-1131.

7. Horwitz, K. B., W. L. McGuire, O. H. Pearson, and A. Segaloff. 1975 Predicting response to endocrine therapy in human breast cancer: a hypothesis. Science (Wash. DC). 189:726-727.

8. Raam, S., N. Robert, C. A. Pappas, and H. Tamura. 1988. Defective estrogen receptors in human mammary cancers: their significance in defining hormone dependence. J. Natl. Cancer Inst. 80:756-761.

9. Berkenstam, A., H. Glaumann, M. Martin, J. Gustafsson, and G. Norstedt 1989. Hormonal regulation of estrogen receptor messenger ribonucleic acid in

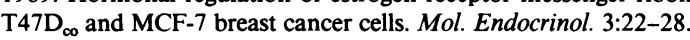

10. May, E., H. Mouriesse, F. May-Levin, G. Contesso, and J.-C. Delarue. 1989. A new approach allowing an early prognosis in breast cancer: the ratio of estrogen receptor (ER) ligand binding activity to the ER-specific mRNA level. Oncogene. 4:1037-1042.

11. Sklarew, R. J., S. C. Bodmer, and L. P. Pertschuk. 1990. Quantitative imaging of immunocytochemical (PAP) estrogen receptor staining patterns in breast cancer sections. Cytometry. 11:359-378.

12. Greene, G. L., P. Gilna, and P. Kushner. 1989. Estrogen and Progesterone receptor analysis and action in breast cancer. In Breast Cancer Immunodiagnosis and Immunotherapy. R. L. Ceriani, editor. Plenum Publishing Corp., New York. 119-129.

13. Kumar, V., S. Green, G. Stack, M. Berry, J.-R. Jin, and P. Chambon 1987. Functional domains of the human estrogen receptor. Cell. 51:941-951.

14. Green, S., V. Kumar, I. Theulaz, W. Wahli, and P. Chambon. 1988. The N-terminal DNA-binding zinc-finger of the oestrogen and glucocorticoid receptors determines target gene specificity. EMBO (Eur. Mol. Biol. Organ.) J. 7:30373044.

15. Klein-Hitpass, L., G. U. Ryffel, and E. Heitlinger, and A. C. B. Cato. 1988. A 13 bp palindrome is a functional estrogen responsive element and interacts specifically with estrogen receptor. Nucleic Acids Res. 16:647-663.

16. Evans, R. 1988. The steroid and thyroid hormone receptor superfamily. Science (Wash. DC). 240:889-895.

17. Green, S., and P. Chambon. 1988. Nuclear receptors enhance our understanding of transcription regulation. Trends Genet. 4:309-314.

18. Beato, M. 1989. Gene regulation by steroid hormones. Cell. 56:335-344.

19. Hughes, M. R., P. J. Malloy, D. G. Kieback, R. A. Kesterson, J. W. Pike, D. Feldman, and B. W. O'Malley. 1988. Point Mutations in the human vitamin D receptor gene associated with hypocalcemic rickets. Science (Wash. DC). 242:1702-1705.

20. Tora, L., A. Mullick, D. Metzger, M. Ponglikitmongkol, I. Park, and P. Chambon. 1989. The cloned human oestrogen receptor contains a mutation which alters its hormone binding properties. EMBO (Eur. Mol. Biol. Organ.) J. 8:1981-1986.

21. Fuqua, S. A. W., S. D. Fitzgerald, G. C. Chamness, A. K. Tandon, D. P. McDonnell, Z. Nawaz, B. W. O'Malley, and W. L. McGuire. 1991. Variant human breast tumor estrogen receptor with constitutive transcriptional activity. Cancer Res. 51:105-109.

22. Horwitz, K. B., M. L. Graham II, and L. A. Miller. 1990. Hormone resistant breast cancer: genetic instability and mutant estrogen receptors. Proc. Am. Assoc. Cancer Res. 31:1269a. (Abstr.)

23. Vedeckis, W. V. 1985. Steroid hormone receptor structure in normal and neoplastic cells. In Hormonally Responsive Tumors. V. P. Hollander, editor. Academic Press, Inc., Orlando, Florida. 3-61.

24. Migliaccio, A., M. Di Domenico, S. Green, A. de Falco, E. L. Kajtaniak, F. Blasi, P. Chambon, and F. Auricchio. 1989. Phosphorylation on tyrosine of in vitro synthesized human estrogen receptor activates its hormone binding. $\mathrm{Mol}$. Endocrinol. 3:1061-1069.

25. Danzo, B. J., 1986. A protease acting on the estrogen receptor may modify its action in the adult rabbit epididymis. J. Steroid Biochem. 25:511-519.

26. Faye, J. C., A. Fargin, and F. Bayard. 1986. Dissimilarities between the uterine estrogen receptor in cytosol of castrated and estradiol-treated rats. Endocrinology. 118:2276-2283.

27. Horigome, T., F. Ogata, T. S. Golding, and K. S. Korach. 1988. Estradiolstimulated proteolytic cleavage of the estrogen receptor. Endocrinology. 123:2540-2548.

28. Sluyser, M. 1990. Steroid/thyroid receptor-like proteins with oncogenic potential: a review. Cancer Res. 50:451-458.

29. Kumar, V., and P. Chambon. 1988. The estrogen receptor binds tightly to its responsive element as a ligand-induced homodimer. Cell. 55:145-156.

30. Klein-Hitpass, L., S. Y. Tsai, G. L. Greene, J. H. Clark, M.-J. Tsai, and B. W. O'Malley. 1989. Specific binding of estrogen receptor to the estrogen response element. Mol. Cell. Biol. 9:43-49.

31. Martinez, E., F. Givel, and W. Wahli. 1987. The estrogen-responsive element as an inducible enhancer: DNA sequence requirements and conversion to a glucocorticoid-responsive element. EMBO (Eur. Mol. Biol. Organ.) J. 6:3719-3727.

32. Bagchi, M. K., S. Y. Tsai, M.-J. Tsai, and B. W. O'Malley. 1987. Purification and characterization of chicken ovalbumin gene upstream promoter transcription factor from homologous oviduct cells. Mol. Cell. Biol. 7:4151-4158.

33. Wang, L. H., S. Y. Tsai, R. G. Cook, W. G. Beattie, M.-J. Tsai, and B. O'Malley. 1989. COUP transcription factor is a member of the steroid receptor superfamily. Nature (Lond.) 340:163-166.

34. Gorski, K., M. Carneiro, and U. Schibler. 1986. Tissue-specific in vitro transcription from the mouse albumin promoter. Cell. 47:767-776.

35. Kumar, V., S. Green, A. Staub, and P. Chambon. 1986. Localisation of the oestradiol-binding and putative DNA-binding domains of the human oestrogen receptor. EMBO (Eur. Mol. Biol. Organ.) J. 5:2231-2336.

36. Fawell, S. E., J. A. Lees, R. White, and M. G. Parker. 1990. Characterization and colocalization of steroid binding and dimerization activities in the mouse estrogen receptor. Cell. 60:953-962.

37. Greene, G. L., N. B. Sobel, W. J. King and E. V. Jenson. 1984. Immunochemical studies of estrogen receptors. J. Steroid Biochem. 20:51-56.

38. Gustafsson, J., S. A. Gustafsson, B. Nordenskjold, S. Okret, C. Silfversward, and O. Wrange. 1978. Estrodiol receptor analysis in human breast cancer tissue by isoelectric focusing in polyacrylamide gel. Cancer Res. 38:4225-4228.

39. Katzenellenbogen, B. S., J. F. Elliston, F. J. Monsma, Jr., P. A. Springer, and Y. S. Ziegler. 1987. Structural analysis of covalently labeled estrogen receptors by limited proteolysis and monoclonal antibody reactivity. Biochem. 26:2364-2373.

40. Marcelli, M. S. Soppi, P. B. Grino, J. E. Griffin, J. D. Wilson, and M. J. McPhaul. 1991. A mutation in the DNA-binding domain of the androgen receptor gene causes complete testicular feminization in a patient with receptor-positive androgen resistance. J. Clin. Invest. 87:1123-1126.

41. Benz, C. C. G. K. Scott, and C. K. Osborne 1991. Identification of non-DNA binding estrogen receptor in tamoxifen resistant breast tumors. Clin. Res. 39:292A.

42. Snedecor, G. W., and W. G. Cochran. 1967. Statistical Methods. Iowa State University Press, Ames. 246-248. 